\title{
Exploring the Explicit Teaching Strategies in STEAm Program of Climate Change
}

\author{
Young Shin Park \\ Corresponding author, \\ Department of Earth Science Education, College of Education, \\ Chosun University, \\ Gwangju, 61452, Republic of Korea \\ parkys@chosun.ac.kr \\ Jo Hoon Park \\ Jin Heung Middle School, \\ Gwangju, 62251, Republic of Korea \\ expert_john@naver.com
}

Received: 15 February 2020 | Revised: 7 May 2020, 9 June 2020 | Accepted: 9 June 2020

\begin{abstract}
The study introduces exemplary explicit teaching strategies as enacted by a middle school STEAM teacher. Through a 10-lesson climate change ST EAM program, data were collected to explore explicit teaching strategies using O-TOP (Oregon Collaborative for Excellence in the Preparation [OсEPT] Teaching Observation Protocol) and NGSS 8 Practices (Next Generation Science Standards). Data from teacher interviews and class observations were also used to identify and describe how this STEAM teacher offered students opportunities to solve real problems in their community. Examples demonstrating three stages of STEAM education: understanding context presentation, performing creative design, and experiencing emotional touch are provided. We argue STEAM programs should be presented with more realistic issues arising from the community students belong to and that explicit teaching strategies should give students the opportunity to achieve core competencies and scientific literacy. Our study offers implications about the need for systemic teacher training and professional development for STEAM education.
\end{abstract}




\section{Keywords}

STEAM - explicit teaching - climate change - O-TOP - NGSS

\section{Introduction}

In the fast-changing society of the 21st century, humanity faces global problems that we have not experienced before: climate change, renewable energy, disease, water shortages, and food shortages. These problems affect us both at the individual and national levels. (Kim et al., 2012; Jeong et al., 2005; UNESCO, 2012). Of course, advanced science and technology fields such as biotechnology, information technology, environmental engineering, and medical technology are developing in ways that improve the quality of our lives. However, behind conveniences allowed by the development of science and technology lie problems such as nuclear power plant accidents, garbage islands, and genetically modified organisms (GMOs), which have gone beyond being simple science problems. Ethically, these developments have had a tremendous impact (Lee et al., 2010; Jeong, 2010; UNESCO, 2012). These problems are damaging our crops due to soil pollution from acid rain and causing direct and indirect damage due to corrosion of buildings and increased respiratory diseases. These problems affect not only individuals but also country-level issues. For example, countries around the world are suffering enormous damage from yellow dust and from fine dust originating in China and other large industrialized nations. In addition, environmental pollution has a tremendous effect on humankind and can even lead to deaths. According to a report released by the World Health Organization (wHO, 2014), one in eight deaths worldwide occurs from air pollution. As such, we can see that our international community suffers seriously from air pollution.

The development of science and technology affects many aspects of society and causes economic problems and political issues among nations, and the development of science and technology has a great influence on human life. In order to adapt to complex international problem situations, adaptable education must start to be provided early on in education systems (NRC, 2000, 2012). However, current curriculums present various shortcomings. The current curriculum in Korea is characterized by fragmentary curriculum knowledge and an entrance examination orientation (MEST, 2015). In order to solve this problem, rather than acquiring fragmentary knowledge like the current curriculum, the emphasis must be on STEAM education (Science, Technology, 
Engineering, Arts, and Mathematics) at home and abroad with convergent thinking ability and creativity (Dare et al., 2019; Park \& Green, 2019). Students also need to improve their actual competence through core competence training through STEAM education, an education innovation shifting from the existing knowledge-based curriculum (Park \& Park, 2018).

The core competencies of STEAM education-convergence, integration, creative design, and emotional experience-are essentials in preparation for global problem solving (Baek et al., 2012). Students need to be exposed to situations where they could face global issues so they are better able to respond flexibly and actively to various issues they face (Park, 2012). To this end, Korea is striving to cultivate the competencies needed in modern society by emphasizing the connection of technology and engineering in the existing mathematics- and science-oriented school education and introducing STEAM education that includes liberal arts elements (MEST, 2011).

Previous research about STEAM have shown that students demonstrated creative and critical thinking skills after STEAM classes (Lee \& Kang, 2014). Jang (2012) conducted a study illustrating that students' perception of STEAM increased due to involvement in integrated education and STEAM education. In addition, the implications and limitations of STEAM education were shown by exploring the perceptions of both pre-service and in-service teachers. Application of STEAm programs in gifted education (Son et al., 2012; Cho et al., 2011) has shown that they were effective in enhancing problem-solving and cooperative-learning competencies that students could apply in their real lives through convergence activities (Heo, 2010).

The examples of previous studies highlight mainly aspects of student perception, teacher perception, and the application of STEAM programs to different levels to determine their effectiveness. But the most important variable for achieving STEAM educational purposes is the teachers themselves. Teachers are the critical and pivotal engine for the students' educational achievement, and the teacher's knowledge system is an important key to the effectiveness of education (Lee et al., 2012). How STEAM education should be applied successfully in the classroom cannot be stated without teachers' explicit teaching strategies resulting from their beliefs. Belief is the act of an individual constructed and integrated by a concept or structure that clings to the truth of the individual (Peterman, 1991). In other words, beliefs, once formed, are difficult to transform and have a stronger impact on actual behavior than other factors. Above all, the educational beliefs of teachers at school sites indicate a strong link between teachers' educational plans, classroom activities, and educational institutions (Heo, 2010; Pajares, 
1992). Teachers' beliefs and practices will affect students' achievements and personality formation; therefore, teachers' explicit and exemplary teaching strategies displayed from their firm understandings about STEAM which are studied and introduced through PDP (professional development program) can promote the meanings and success of STEAM education in other teachers' professions.

Purpose of Study

In this study, by selecting the best STEAM leader teacher, our aim is to explore the characteristics of the teaching strategies that appear explicitly when the STEAM program is implemented. "Explicit teaching/instruction" is a term that summarizes a type of teaching where lessons are designed and delivered to students to help them develop understanding about a topic. Explicit teaching is considered to show clear intention for demonstrating teaching strategies in the class. (Flick, 1995; Tangalakis et al., 2014). The active-teaching perspective explicitly places the teacher at the center of the educational process directing the major activities of the classroom. Explicitly teaching strategies with the clear aim of student achievement (in this study, students experience knowledge and skills in order to be creative problem solvers) must include specific instructional method variables (Flick, 1995; Park, 2008). The explicit teaching strategies of STEAM can be developed and used as guide for understanding STEAM teaching in the classroom so that novice and beginning teachers in STEAM education can improve their teaching skills to master STEAM education. Therefore, it is critical to determine the explicit teaching strategies found in STEAM lessons in order to introduce them as a guide and employ them in professional development program in STEAM education.

\section{$3 \quad$ Methodology}

This study adopts a case study approach, which is considered to be an appropriate qualitative research method (Baxter \& Jack, 2008), in order to observe and explore exemplary STEAM teaching methods to derive explicit teaching strategies as findings. Table 1 below briefly illustrates how this study was designed to select appropriate research subjects, collect data, and analyze data. Detailed information about the research process is given below. 
TABLE 1 The process of the research

\begin{tabular}{|c|c|c|c|}
\hline Steps & 1 & 2 & 3 \\
\hline & $\begin{array}{l}\text { Select an exemplary } \\
\text { STEAM teacher }\end{array}$ & $\begin{array}{l}\text { Collect data (observations } \\
\text { and interviews) }\end{array}$ & $\begin{array}{l}\text { Analyze data and } \\
\text { establish inter-rater } \\
\text { reliability for } \\
\text { observation protocols }\end{array}$ \\
\hline & \multirow{3}{*}{$\begin{array}{l}\text { Select teacher } \\
\text { (Mr. Kim) using } \\
\text { purposeful } \\
\text { sampling for his } \\
\text { expertise in STEAM } \\
\text { education. }\end{array}$} & $\begin{array}{l}\text { Implement STEAM program } \\
\text { of climate change that } \\
\text { authors and the teacher } \\
\text { developed together }\end{array}$ & $\begin{array}{l}\text { Determine patterns of } \\
\text { teaching using O-TOP } \\
\text { and NGSs tools. }\end{array}$ \\
\hline & & $\begin{array}{l}\text { Observe } 10 \text { lessons of } \\
\text { climate change STEAM } \\
\text { program. }\end{array}$ & $\begin{array}{l}\text { Discuss strategies of } \\
\text { teaching in STEAM } \\
\text { to until there is } \\
\text { consensus to ensure }\end{array}$ \\
\hline & & $\begin{array}{l}\text { Analyze using O-TOP and } \\
\text { NGss } 8 \text { practices tool. }\end{array}$ & inter-rater reliability. \\
\hline
\end{tabular}

Note. O-TOP: OCEPT Teaching Observation Protocol (Morrell et al., 2004); NGss: Next Generation Science Standards (NRC, 2012; Kang \& Lee, 2013)

\subsection{Step 1: Select Exemplary Research Subjects}

In the first stage of study, a STEAM master teacher in Korea, Mr. Kim, was selected by convenience sampling with consideration of distance from school and his expertise in STEAM. Mr. Kim holds a Ph.D. in environmental education, and he had had experience in numerous projects related to gifted science education (two projects each year for 7 years), STEAM curriculum research group activities (15 projects of developing and implementing STEAM lessons, remodeling smart classes for STEAM lessons, and evaluating teachers' products for STEAM programs), and development of creative and personality education programs for 13 years (from 2007 to 2020). He has also received awards for being an excellent science guidance teacher. He had had about 30 years of teaching experience and he had taught mainly earth science. Information about his understandings of STEAM that we gained through interviews is given in Table 2.

\subsection{Step 2: Collect the Data}

Data collection to identify the explicit teaching strategies employed two observation tools to observe Mr. Kim during the 10 lessons of the STEAM program on climate change. 
The difference in teaching between science and STEAM lessons

- Students deal with big data from different data sources, so it is critical to provide students the chance to experience the different kinds of data students can face and how to deal with it.

- STEAm lesson have more focus on interaction between teacher and students.

- The role of a teacher is a collaborator rather than a giver.

- Students have more right to do investigation in ways such as deciding variables and selecting tools for investigations for themselves. As a teacher, I provide the materials requested by students.

Critical teaching strategy in STEAM class

- Teachers need to decide when and how to implement steam lessons after revising the curriculums in each component of STEAM.

- Teachers must provide chances for two stages where students face and frame questions from the given phenomenon and where students suggest practical solutions.

- Teachers must interrelate five disciplines for STEAM lessons.

- Teachers must provide students the chance to evaluate what they produce and feel self-achievement and satisfaction in the emotional stage.

- There must be opportunity for students to apply concepts they have learned by giving concrete contexts.

- Teachers must prepare materials for group work that is essential for a STEAM program.

Considerations for successful stEAM lessons

- The safe and efficient use of information, materials, tools, and teaching aids.

- The appropriate content and time arrangement for students.

- Detailed information about students' roles and methods of activities in the group for students' active participation.

- The ability to revise curriculum to be helpful to students' thinking skills. 
My StEAm lessons have:

- Students do group work that includes brainstorming, discussion, and mind-mapping.

- Students problem solving through thinking skills involving framing questions, playing different roles, designing experiments appropriate to the questions.

- Students present their results through posters, role-play, and discussing how to employ their results in the field.

- Students engage in interactive evaluation, self-evaluation, and group evaluation.

3.2.1 Develop the climate change STEAM program

Mr. Kim and the authors (a science educator and expert in STEAM program), who are both familiar with STEAM programs, developed the climate change STEAM program in consideration of the characteristics of the three stages of STEAM education: understanding context presentation, performing creative design, and experiencing emotional touch (Cho et al., 2012; KOFAC, 2017). Table 3 gives a brief description of the program.

The 10 lessons were implemented by Mr. Kim and were recorded as video clips, which were then used by the authors to determine the characteristics of the explicit teaching strategies in the STEAM program. In addition, in order to enhance the validity and reliability of this study, the authors and Mr. Kim discussed their analyses on an ongoing basis in order to reach a consensus.

\subsubsection{Data collection}

Two tools were used in data collection and data analysis. One was observational tool with which the authors were very familiar that had been developed to profile teachers' behaviors by qualitatively measuring the amount of frequency with which reform-based teaching techniques are seen in lessons (Morrell et al, 2004; Park, 2008; Park et al., 2014). The other was the NGss (Next Generation Science Standards) 8 Practices of science and engineering that the framework identifies as essentials for all students to learn, whose aim is to train students to be problem solvers by applying concepts and be knowledgeable by forming concepts (NGSS, 2012; Park \& Green, 2019). 
TABLE 3 The introduction of climate change STEAM lessons

STEAM stage

Context presentation

Creative design

Emotional touch

\section{Content of lessons in STEAM}

Lesson 1

Students were motivated to solve the climate change issues in the community. Students were given an official letter where an official in the government's ministry of the environment offered a chance for students in their school to provide a solution for the community. Students felt responsibility for and belonging to their community.

Lessons 2 to 8

There were several experiments: find evidence showing the change in temperature in the city where the students live, determine critical gases affecting global warming, determine the characteristics of green algae, install a photobioreactor, and evaluate a product from an economic viewpoint.

Lessons 9 and 10

There were two lessons where students introduced a product to determine how efficient it is from economic and environmental viewpoints in reducing and consuming $\mathrm{CO}_{2}$ at the same time.

\subsubsection{O-TOP observation protocol tool (Morrell et al., 2004)}

Morrell, Wainwright, and Flick (2004) developed the O-TOP (Oregon Collaborative for Excellence in the Preparation [OCEPT] Teaching Observation Protocol). O-TOP is an observational instrument, which includes 10 different categories for evaluating the impact of reformed-based professional development activities on classroom teaching practices. Previous studies have shown that exemplary teachers more frequently enact practices measured by O-TOP than beginning and pre-service teachers (Park, 2008; Park et al., 2004). The authors in this study employed the O-TOP to develop explicit teaching categories to be targeted for evaluation while observing Mr. Kim's teaching of STEAM lessons. The O-TOP observation tool has the advantage of being able to profile a teacher's teaching strategies concretely and explicitly. For this reason, O-TOP was used to identify and visualize the features of instruction Mr. Kim employs during his STEAM lessons. In this paper, we refer to each of the ten categories 
in sequence as "O-TOP \#1", O-TOP \#2", etc. Please see Morrell et al, (2004) to access the instrument.

\subsubsection{NGSS (Next Generation Science Standards) 8 practices analysis tool (Kang \& Lee, 2013)}

The eight practices of NGSS detailed by Kang and Lee (2013) describe practices commonly associated with science and engineering. The eight practices of NGSS are (1) ask questions, (2) develop and use models, (3) plan and carry out investigations, (4) analyze and interpret data, (5) use mathematics and computational thinking, (6) construct explanations, (7) engage in argument from evidence, and (8) obtain, evaluate, and communicate information. Other researchers have noted that the NGSS best practices are also useful for achieving the goals of STEAM education (Kang et al., 2015; Park, 2008). Researchers had previoysly created an observation tool based on the NGSS 8 Practices for teachers' competencies of teaching (Kang et al., 2015), which we adopted for this study. In this study, we applied the NGSS eight practice analysis tool to determine whether the STEAM program observed in this research was conducted with a focus on science and engineering. Using this tool, we determined which practices were used in each lesson and whether the practice was used with high, middle, or low frequency. The code "NGSS \#1-1" means the first description in the first practice of the eight NGSS practices. There are are total of 46 elements described in relation to the NGSS 8 practices (Kang \& Lee, 2013; NRC, 2012).

\subsection{Step 3: Analyze the Data}

The о-тоP observation tool (Morrell et al., 2004) and the NGSs practice analysis tool (Kang \& Lee, 2013) were used through cross checking and consensus discussion in analyzing the data. From these two data collection sources, we created a table that included the major components of the O-TOP and NGSS 8 Practice tools, profiling the participating teacher's explicit behaviors in the STEAM lessons.

\subsubsection{O-TOP tool}

The frequency of teaching strategy was given o to 4 points indicating relative frequency, with the most frequent ( 3 and 4 points) being the constituent elements of the strategy that appeared most at each stage. There were also o- to 2-point activity factors, but analysis using this tool aimed to identify the teaching strategy by activity elements with 3 and 4 points. In addition, the validity and reliability of the data were built internally by the researchers, including one who developed 
the O-TOP observation tool (Cho, 1999; Park et al., 2004). In other words, through the practice and discussion with the development researchers, the validation of data analysis was constructed. The code "О-тор \#3" means student discourse and collaboration: encouraging students to develop discourse in groups.

\subsubsection{NGSS 8 practices analysis tool}

When using this tool, the relative frequency of a teaching strategy was determined to be high, medium, or low, with the teaching strategy appearing most often being the activity element that composed the strategy at that stage. Of course, there can be other elements of medium and low activity, but the analysis using this tool aimed to clarify the teaching strategy as the element of greatest activity. In addition, for validity and reliability, we analyzed the data and agreed on overall opinions. In analyzing the classes observed during the STEAM lessons, it was important to determine whether the eight practices presented from the scientific and engineering perspective were included or not. The code "NGSS \#1-1" indicated the first description in the first practice of the NGSS 8 Practices: encourage students to frame questions about the nature shown to them.

\section{$4 \quad$ Results}

The purpose of this study was to profile the explicit teaching strategies displayed by an exemplary teacher during STEAM lessons. As a research method, a 10-lesson STEAM program was developed in collaboration with a teacher, Mr. Kim, and steAm lessons were observed and recorded on video, and the researchers categorized explicit STEAM teaching strategies. The profile of the explicit teaching strategies used by Mr. Kim during STEAM classes with the most frequently used teaching strategies will be discussed in the first part. A more detailed description of the teaching strategies used with high and moderate frequency will be introduced in the second part.

\subsection{Explicit Teaching Strategies in the Context Presentation Stage}

The following shows the most commonly used of the teacher's practices captured by NGSS and O-TOP. The most frequently occurring strategies are provided first, and those that occurred less frequently are included in each result section (see Table 4). 
TABLE 4 Explicit teaching strategies frequently employed in context presentation stage

NGSS (Next Generation Science Standards) 8 Practices analysis tool

No Practice

\#1 Ask questions

The ability to form empirically answerable questions about phenomena, establish what is already known, and determine questions that have not yet been answered.

\#6 Construct explanations

As the goal of science, construct a theory that provides an explanatory system that describes the material world.

\#7 Engage in argument from evidence

Defend the narrative system, form evidence on a solid foundation of data, test understanding using evidence and other people's advice, and work with colleagues to provide the best explanation for the phenomena investigated.
Elements of Practice

1-1: Ask about nature and the human-made

world

1-3: Ask questions that can be answered using materials in the classroom, refine the questions, and use them to devise inquiry or construct practical solutions

1-4: Ask questions that confirm the premise of the argument or ask for additional explanation. Ask questions that require refinement of research questions or engineering problems, or questions that challenge interpretation of the material. 1-6: Ask questions to identify the limitations that affect the solution 6-3: Suggest an appropriate level of causal explanation

7-1: Construct a scientific debate that shows how the data support the claim 
TABLE 4 Explicit teaching strategies frequently employed in context presentation (cont.)

O-TOP observation protocol tool

No. Focus

\#3 Student discourse and collaboration

\#5 Student preconceptions and misconceptions

\#7 Divergent thinking

\#10 Multiple representations of concepts

\section{Descriptor}

Interactions reflected collaborative working relationships and productive discourse among students/between teacher and students.

The instructional strategies probed students' existing knowledge and preconceptions.

Students were encouraged to generate conjectures, alternative solution strategies, and ways of interpreting evidence.

The teacher used a variety of means to represent concepts.

In addition to these most frequent teaching practices captured through O-TOP and NGSS, there were also moderate- and low-frequency practices determined by O-TOP and NGSS. The most frequently used practices identified by the O-TOP and NGSS tools profiled explicit teachings as asking questions, constructing explanations, engaging students in argumentation, and making more chances for student discourse. By means of these practices, Mr. Kim checked students' knowledge and promoted thinking skills through various teaching materials, which were observed in the beginning stage of the STEAM program context presentation.

The stage of context presentations included the first of the 10 lessons. The first lesson was where Mr. Kim introduced the project involving situations of global warming caused by $\mathrm{CO}_{2}$ to the students. Students were then encouraged to do brainstorming with peers in a group to find the most effective solution (Figure 1). Mr. Kim pretended that he had received an official letter from

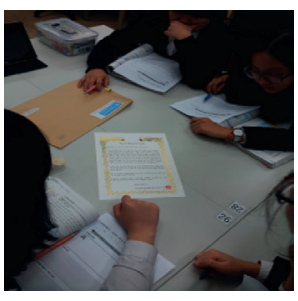

FIGURE 1

An official letter to students to identify issues related to climate change 
government to motivate students to face the issue and feel responsible to solve the problem. This gave students feelings of responsibility and belonging in that they were representing the community to solve this problem.

The explicit teaching strategies observed and identified in the problemraising phase are as follows on the basis of analyses in NGSS and O-TOP.

4.1.1

Employ Open Questions Linked to Real Life rather than Virtual Life

Mr. Kim showed a video on the causes of climate change and presented open questions about what caused climate change, what global warming is, what the greenhouse effect is, and how climate change is caused by greenhouse gases, such as carbon dioxide at the beginning of the lesson (NGSS \#1-1: asking questions and defining problems/asking questions that arise from careful observation of phenomena, models, or unexpected results, clarifying and seeking additional information).

The environment or the earth is something we feel with all our senses, but it's not visible, and what's actually happening isn't like we're seeing a fire like a car accident at this moment. The damage doesn't come to us quickly. That's why we always miss it [class observation]

Is green algae caused by global warming?.... What does it mean if it's [algae] green? ... photosynthesis. When photosynthesis comes in, what does it want? It takes in carbon dioxide and puts out oxygen, right? Then wouldn't it be good to have a lot of green algae in the river? Don't you think so? Doesn't it use carbon dioxide too? It's going to use it, and it puts out oxygen, so if we get rid of carbon dioxide, we can solve the climate change problem, so we can think the green water can help to solve the climate change problem? But there's a trap there. What kinds of pitfalls are there? [class observation]

Mr. Kim also examined students' prior concepts about global warming and asked many divergent questions to identify students' levels in concepts related to climate change (O-TOP \# 7 : divergent thinking), through which teacher accepted multiple responses to problem-solving situations. Mr. Kim also encouraged students' participation in the discussion by explaining the changes in climate that students could face in their daily lives after considering students' levels in concepts of climate change (O-TOP \#5: students' preconceptions and misconceptions, О-TOP \#9: pedagogical content knowledge). 
Mr. Kim gave students a real-world issue, climate change, that they could feel in their lives and was not just a vague phenomenon (NGSS \#1-3: ask questions that can be answered using materials in the classroom, refine the questions, and use them to devise inquiry or construct practical solutions; NGSS \#7-1: construct a scientific debate that shows how the data support the claim). To make it more realistic, Mr. Kim made students feel more responsibility by assuming a national emergency, and as youth environmental engineers, students brainstormed to solve the task of mitigating global warming and developed their ability to cope with situations (NGSS \#1-4: Ask a question to confirm the premise of a controversy or ask for an additional explanation. Ask a question that requires elaboration of a research question or engineering problem or ask for a challenge to the interpretation of the material.).

To help students think challengingly (O-TOP \#5: students' preconceptions and misconceptions), students were encouraged to be youth environmental engineers and they were given the opportunity to discuss the impact of climate change on their society. Mr. Kim provided the following mission: Determine the most effective solution to reduce or mitigate global warming (O-TOP \#3: student discourse and collaboration). Students discussed what might be the best solution for their community by providing practical experience in connection with real life.

You are given a mission. What is the mission? ... The mission of the National Environmental Emergency Response Commission to each group. Open it. What does it say? We can solve the problem? How? [class observation]

It is very critical to use group-led activities through creative strategies such as live brainstorming, mind-maps, and discussion, and students could explore their opinions about the solution. This can be very active when students feel responsibility to the community to solve the problem. [interview, Mr. Kim]

\subsubsection{Exchange Opinions from Various Perspectives with the}

Responsibility of Finding a Real Solution

The special assumption of crisis in a national context allowed students to discuss and conclude with each group on the impact of global warming. This gave students feelings of responsibility and pride that they would be in charge of a large and important task in facing a great crisis in the country, and they 
developed the ability to cope with situations without hesitation (о-тор \#3; student discourse and collaboration; О-тоР \#6: conceptual thinking). Mr. Kim conducted brainstorming for students' problem-solving efficiency and discussed with students how to use it (O-TOP \#10: multiple representations of concept).

Through collaborative learning, team members shared their ideas about climate change, then discussed their own issues that needed to be resolved by the group. Mr. Kim also encouraged students to explore the solution to climate change phenomena through questions (O-TOP \# 3 : student discourse and collaboration; О-тоР \#4: rigorously challenged ideas; о-тоР \#6: conceptual thinking). Communicating with peers to solve an urgent crisis helped students to show the fellowship and belonging through which students could face and collaborate to find a solution as a team rather than as individuals (о-тор \#2: metacognition: students' thinking about their own thinking). Mr. Kim also let students brainstorm effectively and helped them improve their competencies in arranging many tasks on their own and then organizing their ideas more clearly (О-тоР \#10: multiple representations of concepts).

What earth problems will come in the future, especially in terms of climate change; what are some ideas? [class observation]

I think it is pivotal for students to make a group and share their opinions from different points of view in order to understand and solve a problem. In order to accomplish this, I make groups in each science class and let students play different roles in the class. This is my role. I emphasize the group work more than individual work. [interview, Mr. Kim]

Overall, in the first questioning stage examined using the NGSs tool, open questions, motivation through realistic problems, and exchange of opinions through cooperative learning were most explicitly demonstrated during the lessons. The O-TOP analysis showed that Mr. Kim helped students to learn science by asking open questions, encouraged them to present their various views about climate change, encouraged them to approach the problem with more realistic attitudes, responsibility, and pride. Teaching strategies of using the real context of climate change in the community and posing open questions for divergent and creative thinking were identified as having the potential to help students be motivated to solve the problem.

\subsection{Explicit Teaching Strategy in the Creative Design Stage}

The creative design phase corresponds to Classes 2-8 of the program. In the creative design phase, students explored activities connected to climate 
TABLE 5 Explicit teaching strategies frequently employed in creative design stage

NGSS (Next Generation Science Standards) 8 Practices analysis tool

\section{No Practice Elements of practice}

\#3 Plan and carry out an investigation

Plan and carry out an investigation: The ability to plan and carry out a study that identifies data in the field or identifies variables in an experiment.

\#4 Analyze and interpret data

The ability to produce data that must be analyzed, identify significant element and patterns in the data set, determine the cause of error, and calculate the confidence interval.

\#6 Construct an explanation As the goal of science, construct a theory that provides an explanatory system that describes the material world.
3-1: Construct questions that can be studied in a classroom, school lab, or field and, if possible, establish hypotheses based on a theory or model 3-2: Determine what data is needed, what tools are needed to collect the data, and how measurements are to be recorded 3-4: Plan experimental or field study procedures and check the control variables if necessary for the relevant independent and dependent variables 3-5: Design the investigation after controlling the intertwined variables

4-1: Interpret data systematically to determine patterns or to test if the data is consistent with hypothesis

4-3: Use databases, tables, charts, graphs, mathematics, statistics, and computer technology for data integration and organization, and investigate the relationships between variables

6-1: Construct a description of the phenomenon using scientific theory and linking it to models and evidence 6-2: Support or refute an explanation of a phenomenon using direct and indirect scientific evidence and models 6-3: Suggest an appropriate level of causal explanation 6-6: Create a plan that meets the criteria and participate in the entire design process to accomplish design challenges

6-7: Create a device or troubleshoot design problems 
TABLE 5 Explicit teaching strategies frequently employed in creative design stage (cont.)

\section{NGSS (Next Generation Science Standards) 8 Practices analysis tool}

\section{No Practice Elements of practice}

\#7 Engage in an argument 7-1: Form a scientific debate where data show how from evidence an argument is supported

The ability to defend $\quad 7-3$ : Find fault in one's discussions and improve in the explanatory system, response to refutation form evidence on a solid 7-7: Reveal strengths and weaknesses of science and foundation of data, test technology understanding through evidence and other students' advice, and work in a group to obtain the best explanation.

\section{O-TOP observation protocol tool}

No. Focus Descriptor

\# $1 \quad$ Habits of mind

\#2 Metacognition

\#3 Student discourse and collaboration

\#4 Rigorously challenged ideas

\#10 Multiple representations of concepts
The lesson encouraged students to seek and value various modes of investigation or problem solving. Students' thinking about their own thinking . Teacher encouraged students to be reflective about their learning.

Interactions reflected collaborative working relationships and productive discourse among students/between teacher and students.

Intellectual rigor, constructive criticism, and the challenging of ideas were valued.

The teacher used a variety of means to represent concepts. 
change concepts. Below Table 5 lists the most frequently occurring practices in the NGSS and O-TOP analyses. The most frequently occurring strategies are provided first, and those that occurred less frequently are included in each result section.

Here, the teaching strategies in this stage of creative design in the program included planning and carrying out an investigation, constructing an explanation, engaging in an argument from evidence, encouraging students to seek and value various modes of investigation, encouraging students to think about their thinking, making discourse and collaboration, promoting students' thinking skills, and using various means for concept understanding. Mr. Kim promoted students' discourse and argumentations in the creative design stage in data collection, analysis, and interpretation. Most of all, Mr. Kim provided a chance to seek and value various modes of investigation.

The following description is a brief summary of the activities of each class given by Mr. Kim. In the second lesson, students analyzed the actual data on the distribution of monthly temperature and rainfall in Korea for the last 5 years to grasp the trends of Korean climate change (Figure 2).

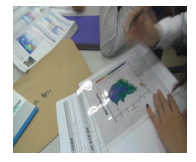

FIGURE 2

Analyzing the trend of climate change in Korea for the last 5 years

In the third lesson, students worked in groups with Mr. Kim's guidance to make a hypothesis about how heat-absorbing film could be used to explain how the greenhouse effect occurs. Students desiged and verified their hypothesis via experimental activity (Figure 3). In the fourth lesson, the teacher encouraged students to select the possible gases causing global warming, and students had the chance to select different independent variables (dry or moist air, dry ice, etc.) to see their effect on temperature increase as dependent variables. Dry ice was used to reproduce the greenhouse effect of real gas, thereby helping students understand the effect of carbon dioxide as a major cause of global warming. Mr. Kim encouraged students to select the possible gases using evidence from their own knowledge. Mr. Kim challenged students to design experiments based on the logical hypothesis (Figure 3).
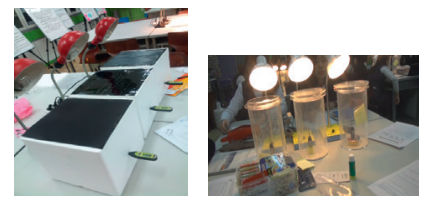

FIGURE 3

Experiments on the greenhouse effect and the main gas affecting global warming 


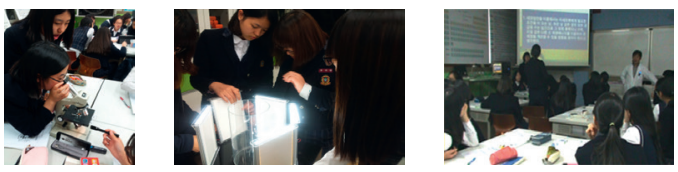

FIGURE 4 Lessons exploring using green algae to reduce $\mathrm{CO}_{2}$

In the fifth lesson, algae was observed under a microscope to investigate its characteristics, and then the possibility of carbon dioxide reduction using algae was explored (Figure 4). The sixth and seventh lessons were based on the fifth one, examining how photobioreactor devices were designed to use green algae biomass as carbon dioxide reduction technology with low cost, high efficiency, and scientific accuracy. The study was conducted as a group of students and Mr. Kim asked the students to determine how they could know whether there was a reduction in $\mathrm{CO}_{2}$ and when (at the maximum point of photosynthesis) they would stop running the photobioreactor. In the eighth lesson, Mr. Kim prepared students to introduce the outcome of the usage of the photobioreactor to each group, and the teacher let students compare products from the point of view of economics, the environment, and society.

The explicit teaching strategies observed and identified in the creative design stage are as follows.

\subsubsection{Provide the Chance to Design Experiments with Various Tools in Abstracting Complex Contexts}

Mr. Kim stimulated students' thinking through open questions such as "What are the effects of global warming?" and "How does the greenhouse effect affect our lives?" After recognizing that five years of data was insufficient, ten years of data for Korea's temperature and precipitation were distributed to students to examine and determine the pattern of climate change. In addition, students were asked to find data using various media related to climate change. Using tablet PCs, standing tables, and other resources, students were able to actively collect relevant data for 10 to 20 years by controlling appropriate variables for each group. Students were asked to convert the resultant values to graphs on the paper, where Mr. Kim checked students' competencies in data-related practices. Students identified the patterns of change at a glance and indicated how changes in precipitation and temperature affected their real life (NGsS \#4-1: systematically interpret data to find patterns or test data for consistency with hypotheses; NGSS \#4-3: use spreadsheets, databases, tables, charts, graphs, mathematics, statistics, and computational techniques and examine the relationships between variables; NGSS \#7-1: construct a scientific debate that shows how data support arguments). 


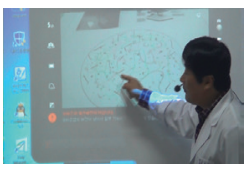

FIGURE 5

Students share their views on climate change using smartphone apps to mirror and project their data to the class projector

Mr. Kim had students use the tablet PC to reflect what they had discussed with the group, telling their peers what they had discussed in groups. In addition, the teacher let students observe the green algae to see its composition through microscope (Figure 5). In addition, Mr. Kim prepared whatever kits were necessary to perform actual experiments that the students themselves designed (о-тоР \#4: rigorously challenged ideas; О-TOP \#10: multiple representations of concepts).

Did you use tools here? What tool? A microscope? What else? Write down or draw what you see.... Underneath, let's find and organize the characteristics of microalgae using tablet PC information from the Internet. [class observation]

You do not have any feeling about climate change so far. Cold? Yes, it is. Hot? Yes, so what? You have thought about climate change like this. Now, you can determine the symptoms of global warming through a variety of data. How? [class observation]

My role as a teacher is to provide what students need. Using technology for better science learning is essential for STEAM classes. [interview, Mr. Kim]

\subsubsection{Promote Problem-solving Processes Connected to Students' Real Community}

Mr. Kim used materials that students could find in their daily lives. Experiments by shining light on heat absorbing plates, cellophane paper, and film plates on styrofoam helped students to see how the change in temperature affected each of the other variables to recognize the greenhouse effect in real life (NGSS \# 3 -1: construct a question that can be studied in a classroom, school laboratory, or field and, if possible, establish a hypothesis based on theory or model; NGSS \#3-4: plan an experimental or field research procedure and involve independent variables and dependent variables, if necessary, and identify the control variables; NGSS \#4-1: interpret data systematically to find patterns or to test whether data are consistent with hypotheses).

Mr. Kim prepared three kinds of variables (carbon dioxide, water vapor, and general dry air) that cause global warming and gave students enough time to 
think about what each variable is and how it can cause global warming. The greenhouse effect was reproduced using gases to help students confirm that carbon dioxide plays an important role as a greenhouse gas (NGSS \#3-1: construct a question that can be studied in a classroom, school laboratory, or field, and, if possible, establish a hypothesis based on theory or model; NGSS \#3-4: plan experimental or field research procedures and identify relevant independent and dependent variables; 0-тор \#4: rigorously challenged ideas).

What is the effect of the greenhouse? ... Is it because of carbon dioxide? But does carbon dioxide really raise the temperature higher than other things do? How can you know? Can you prove logically using experiments? ... Are you really confident that carbon dioxide causes global warming more than anything else? [class observation]

How do you know that photosynthesis is going on? By color? How do you know when to stop running this bioreactor? Is this bioreactor efficient in Korea? Everywhere? Is the cost effective? If you own chemical factory, will you use this bioreactor? [class observation]

Mr. Kim was also confident that he gave students the chance to develop higherlevel thinking and scientific inquiry skills by encouraging them to abstract the phenomena to be decomposed so that it could be manageable for their inquiry.

I expect students to gain experience in promoting their thinking skills scientifically and computationally. They can also gain experience emotionally by evaluating their product from the different points of view. Emotional experience must be trained too. [interview, Mr. Kim]

Mr. Kim checked students' prior knowledge about climate change then provided them the issues of climate change. Mr. Kim encouraged students to use their concepts to explore climate change and global warming (NGSS \#3-4: plan experimental or field research procedures and identify relevant and dependent variables, if necessary, and control variables; NGSS \#6-3: propose an appropriate level of causal explanation). Mr. Kim did not provide any new terms, causing students to hesitate in solving the problem. Mr. Kim asked students to explore the characteristics of green algae using tablet PCs directly through divergent 
questions. Students designed carbon dioxide reduction technology using biomass, and students had the chance to go further and discuss the cost and efficiency of manufacturing scientifically accurate devices (NGSS \# $3-2$ : determine what data to collect, what tools are needed to collect it, and how to record measurements; NGSS \#3-5: design the study considering the likelihood or effect of tangled variables control; NGSS \#6-1: utilize scientific theory and link it with models and evidence to construct explanations of phenomena; NGSS \#6-2: explain phenomena using direct and indirect scientific evidence and models to support or refute; NGSS \#6-6: develop a plan that meets standards and participate in the overall design process to perform design challenges; NGSS \#6-7: create a device or solve a design problem).

How can we reduce carbon dioxide? We have many chemical factories in our community. Is there a way to reduce $\mathrm{CO}_{2}$ that is most appropriate to our community? Have you ever seen algae on TV? Was it presented as good or bad? [class observation]

Ten years ago, did we worry about climate change like this? Today we talk about climate change, which is caused by global warming.... It's a story where you can determine the symptoms of global warming through various data, even in our city. [class observation]

Overall, Mr. Kim tried to help students grasp what the problem is, how serious it is, how they could solve it, what the best solution is, and whether that solution is most efficient in the community, all of which were possible from their own knowledge and the teacher's input.

4.2.4 Play the Role of Collaborator Rather than Information Provider Mr. Kim did not end with the completion of the work, but instead he presented a prototype model of the $\mathrm{CO}_{2}$ reduction device, compared it with another one and stimulated students to provide the idea of pros and cons for the best solution. Students gave feedback to each other by not only accepting but also defending the opinions of others (NGSS \#7-1: construct a scientific debate showing how the data support the claim; NGSS \#7-3: find deficiencies in the discussion and improve its through criticism; NGSS \# 7-7: critically read media reports on science and technology to identify strengths and weaknesses). Mr. Kim acted as a collaborator and a learner by doing experiments together. When Mr. Kim presented his ideas to students' groups, he critically accepted and advised the students' misconceptions related to microalgae from the same peers' point of view (о-тоР \# 7 : divergent thinking; О-тоР \#8: interdisciplinary connection). In 
addition, Mr. Kim suggested to students appropriate variable controls in relation to greenhouse gas and greenhouse effect experiments and induced them to indirectly experience the causes of climate change (О-TоP \#4: rigorously challenged ideas; О-тОР \#6: conceptual thinking; О-тОР \#7: divergent thinking; O-TOP \#8: interdisciplinary connections). In the following class observation and interview, Mr. Kim emphasized the teacher's roles as a collaborator.

There is a Styrofoam box. There's a front and back side, right? Is there a difference between these sides in temperature? ... Then measure the current temperature and measure the temperature every minute. But before measuring, do we need to check the current temperature of the classroom and inside of the box before installing the thermometer? And now, when you turn on the light for photosynthesis, it's time to keep track of how much the temperature changes in 1-minute interval. [class observation]

Sometimes I feel uncomfortable when I face issues I am not familiar with, so it is very important for teachers to be knowledgeable enough in what they are doing in both experiments and content. I encourage students as a collaborator to think differently and make arguments by proposing a product's pros and cons. [interview, Mr. Kim]

\subsubsection{Make Learner-centered Science Class though Strong Communication}

When discussing greenhouse gases and greenhouse effect experiments and designing and developing a carbon dioxide reduction tool (photobioreactor), Mr. Kim encouraged students to exchange their ideas with each other in order to reach their learning goals for the solution. The cooperative learning aspect was highlighted so that peers could exchange creative ideas actively (о-тоР \#3: student discourse and collaboration; О-TOP \#5: students' preconceptions and misconceptions; O-TOP \#6: conceptual thinking). The following communication in a group shows how students in a group interacted with each other.

Student 1: Make a $\mathrm{CO}_{2}$ reducing tool?

Student 2: Write down your ideas, and we need to make a device to promote photosynthesis.

Student 3: Are these three materials enough?

Student 2: Well, I think we should have this, since we need to cultivate green algae, right? Then I think we need this kit too. We can install them? оK, let's follow the steps. Let's write down the process first. [class observation] 
In the conversation above, students did not seem to have the right answer. Instead, they struggled to select the materials for creating a tool for reducing $\mathrm{CO}_{2}$ and discussed what kinds of work they could do. This was a result of Mr. Kim asking them what sequence of steps they needed to take and encouraging them to interact with each other for the best solution in each group. Mr. Kim added that it was very critical for students to determine and keep in mind what they would do and why and how they would do it in order to reach a solution. For this goal, Mr. Kim emphasized students' intentions and responsibilities from their motivation to solve the given problem.

Overall in the second phase of the STEAM program, the creative design stage, the most prominent teaching strategy items examined through the NGSS tool included Mr. Kim's employing of various media and experiments in a real life-like experiment, implementing divergent questions through familiar data, and providing feedback as a collaborator. The discussion among students or with students was based on evidence from experimentation. Analysis using the O-TOP tool showed that the most frequently used strategies in the creative design phase were related to tasks of how to help students feel the responsibility to solve the problems, how to bring the issue of climate change to the classroom in a more realistic way so that students felt motivated to face that issue, and what solution students came to think was the most appropriate in their city. Those tasks were conducted through a variety of media, experiments, and discussion where Mr. Kim played the role of collaborator with the students in designing the investigation, encouraging them to suggest, refute, and confirm what they had done as a collaborator and creating opportunities for communication.

\subsection{Explicit Teaching Strategies in the Emotional Touch Stage}

The emotional touch stage corresponded to Lessons 9 and 10 of the 10 lessons. In the emotional touch stage of the program, students presented a carbon dioxide reduction plan as the final product of the project. In the ninth class, the $\mathrm{CO}_{2}$ consumption system was improved in each group by conducting effective green algae dispersion and effective condensation for photosynthesis and testing the amount of carbon dioxide consumed. This was a step designed to determine ways to mitigate climate change in life. The following shows the most frequently occurring practices in the NGSS and O-TOP analyses. The most frequently occurring strategies are provided first, and those that occurred less frequently are included in each result section (see Table 6). 
TABLE 6 Explicit teaching strategies frequently employed in the emotional touch stage

NGSS (Next Generation Science Standards) 8 Practices analysis tool

No Practice

\#7 Engage in an argument from evidence

The ability to defend the explanatory system, form evidence on a solid foundation of data, test understanding through evidence and other students' advice, and work in a group to obtain the best explanation.

\#8 Obtain, evaluate, and communicate information The ability to communicate the results of thought by participating in open discussions with peers using words, writing, tables, pictures, graphs, and equations, using information to evaluate the scientific validity and to produce the explanation.

\section{Elements of Practice}

7-1: Form a scientific debate where data show how an argument is supported 7-3: Find fault in one's discussions and improve in response to refutation 7-7: Reveal strengths and weaknesses of science and technology

\section{O-TOP observation protocol tool}
No. Focus
Descriptor

\# 1 Habits of mind

The lesson encouraged students to seek and value various modes of investigation or problem solving.

$\#_{2}$ Metacognition

Students' thinking about their own thinking: Teacher encouraged students to be reflective about their learning. 
TABLE 6 Explicit teaching strategies frequently employed in the emotional touch (cont.)

NGSS (Next Generation Science Standards) 8 Practices analysis tool

No Practice

\#3 Student discourse and collaboration

\#6 Conceptual thinking

\#9 Pedagogical content knowledge

\#10 Multiple representations of concepts
Elements of Practice

Interactions reflected collaborative working

relationships and productive discourse

among students/between teacher and students.

The teacher promoted strongly coherent conceptual understanding in the context of clear learning goals.

The teacher had a solid grasp of the subject matter content and how to teach it.

The teacher used a variety of means to represent concepts.

In this stage, Mr. Kim's teaching strategies included engaging in arguments from evidence, communicating information, encouraging students to seek and value modes of problem solving, encouraging students to be reflective about their learning, showing strong PCK, and using various means for representing concepts. The explicit teaching strategies observed and identified in the emotional experience stage are as follows.

\subsubsection{Use Various Media to Consider Realistic Problems and Make Voluntary Experimental Process}

Mr. Kim asked students to directly determine whether the $\mathrm{CO}_{2}$ reduction device using microalgae was effective or not and then determine how effective it was through the acid base measurement method using в в в solution (NGSS \#7-1: construct a scientific debate showing how the data support the claim; NGSS \#7-5: describe the nature of the issue in the development of a given scientific thought, describe the debate at its starting point, and identify why a particular theory was successful). An appropriate analogy was used to allow students to participate in the experiment under appropriate conditions. Mr. Kim explained the metaphors for the students to understand the control of the experiments (o-TоP \#10) and led them to recount their learning goals. 
Let's complete the installation of the photobioreactor today.... You have to measure its change at the same time every day. The same conditions must be maintained during measurement. Observing it from the right, from the left, and from the top is not good measuring skills. Observe its color today? Smell it tomorrow? Taste it? This are not good skills in measuring certain variables. Everyone in the group should make a decision about what data you need, how you measure them, and how you transfer them for interpretation. [class observation]

It is a good way to help students have a habit of applying the concepts they have learned today to their real life. So I am trying to present concrete examples and cases where students could apply their concepts. [interview, Mr. Kim]

In these quotes, Mr. Kim talked about training students to be equipped with basic inquiry skills and observation skills and to be more professional in conducting investigations in the real-life conditions. Mr. Kim also put the emphasis on training students to apply their concepts to real life.

4.3.2 Evaluate the Effectiveness of the Final Product from Various Points of View

Mr. Kim once again reminded students of their awareness of climate change as they lived in the global era (NGSS \#8-3: recognize the characteristics of science and technology and express them in writing and words). The most prominent teaching strategy items in the emotional touch stage found through the NGSS tool were connected to the process of students' hands-on experience and communication in verifying the contents of the experiment. The value of the final product was discussed as a class. Mr. Kim summarized what students might have learned in the prior stages of the program and helped students to think logically and critically of how the suggested tool (a photobioreactor) was the best solution in their city. Students were encouraged to discuss its value from economic, political, and environmental points of view as well as societal. In addition, Mr. Kim challenged students to decide whether photosynthesis was progressing and if the photosynthesis by green algae had reached its peak and had stopped. The втв indicator, which uses color change to check for the existence of $\mathrm{CO}_{2}$, was suggested by Mr. Kim to identify whether students could notice changes in $\mathrm{CO}_{2}$ levels (O-TOP \#6: conceptual thinking).

I'm going to use this to turn on the light and grow green algae.... Finding the location with the best conditions is an important factor.... What does 
the second one to do? Here you see colored paper. Now what does this color mean? ... Can light be more efficient than now? Then there's cellophane inside. This cellophane is transparent acrylic. There is a mirror too.... It's time for you to make choices and find the best conditions for the optimal microalgae today. [class observation]

A teacher needs to provide chances for students to connect climate change to environmental disaster. How can students determine whether climate change can affect environment? Which is connected to human beings? How do they know if the photosynthesis had reached its peak and stopped? We cannot stop running photosynthesis by using color only. We need to save time and money when producing the final product, so I encourage students to think how to change analog data to digital data by finding digital data resources. [interview, Mr. Kim]

In these quotes, Mr. Kim emphasized students' trials in producing the final product. Students experienced applying concepts in the context of engineering and technology. Students tried to find the best kit that would indicate when to stop photosynthesis while they ran the photobioreactor. Rather than using an analog measuring instrument, Mr. Kim mentioned using a digital one where students could read the data on a computer and could stop when the instrument sends a number that could be transferred to the signal by sound or color.

Overall in the emotional touch stage NGss tool showed that students were allowed to think more scientifically, which led to discussions, information gathering, and evaluation and communication based on evidence, where students evaluated the pros and cons of products. Analysis using the о-тор tool showed that Mr. Kim asked students to think of a product's value in real life in terms of how they could produce a product appropriate to their city's needs, how they could save the money and time in producing the product, and how much those products could be efficient in the solution of climate change.

The explicit teaching strategies in the STEAM program on climate change in this study can be summarized as follows in Table 7 .

There are three stages in STEAM lessons. The context presentation phase displayed the teaching strategies of employing open questions linked to the real world as non-virtual experiences and giving a specific challenge to students to realize that climate change was a real problem in their community. In addition, in order to find a solution to a problem in an extreme crisis, it was necessary to exchange opinions through cooperative learning with peers in groups. Mr. Kim presented an extreme situation through which students could feel empathy in reality and could be motivated to save the community. 
TABLE 7 Summary of explicit teaching strategies in the STEAM program on climate change in this study

Stage $\quad$ Explicit teaching strategies found in the STEAM lesson

Context

- Employ open questions linked to real rather than virtual life.

presentation - Motivate students to realize the problem with the given specially designed task.

- Exchange opinions from various perspectives under the responsibility to find a real solution.

Creative design - Provide chance to design experiments with various tools in abstracting complex contexts.

- Promote problem-solving processes connected to the students' real community.

- Use familiar everyday materials and information for abstracting the phenomena in considering a real problem.

- Play role as a collaborator rather than information provider.

- Make a learner-centered science class though strong communication.

Emotional touch - Use various media to consider a realistic problem and make it a voluntary experimental process.

- Evaluate the effectiveness of the final product from various points of view.

During this stage, Mr. Kim's main roles included challenging, stimulating, encouraging, and suggesting students to realize, understand, and learn concepts through communication and collaboration.

The creative design phase included Mr. Kim's role of encouraging students to think of ideas/materials related to their real life for practical solutions and to design experiments possible in the real situation by considering realistic rather than virtual variables. These are examples of activities that promoted abstraction and computational thinking practice. In addition, various media/ materials were considered and chosen by students, who then took the steps according to their plan from redefining the questions to evaluating the appropriateness of the product. Last, in the emotional touch phase, Mr. Kim let students experience an appropriate analogy to evaluate the product where students decomposed the given situation in realistic way. In his interview after the lessons, he added difficulties and satisfactions with them and improvements for better STEAM lessons (see Table 8). 
TABLE 8 Summary of pros, cons, and needs for improvement of STEAM lessons

The difficulties in carrying out STEAM lessons-need to

- adjust lessons to individual levels in the class

- promote absent students' participation in group work

- meet learning objectives within the assigned time

- improve the validity and reliability of evaluating students

- prepare a variety of materials or tools

- overcome fear and discomfort arising from lack of experience in STEAM and lack of employing teaching skills for students' involvement

Satisfaction with STEAM lessons-offers students a chance to

- design a photobioreactor to reduce $\mathrm{CO}_{2}$

- measure the level of photosynthesis in cultivating green algae qualitatively and discuss how to measure them quantitatively

- collect and analyze the various data about causes and damage of climate change

- experience the process of explaining and understanding climate change and the global warming environment

- understand climate change in various ways, establish a solution, and have a willingness to implement it, at least in the local community

Plans for how to improve the STEAM lessons in the future

- replace green algae used in lessons with another that is easier to obtain

- present results in a variety of ways that are of interest to students (role playing, making a newspaper, or dancing)

- present a plan to confirm the willingness to perform the actual practice after the STEAM class is over

- make diagnosing seasonal climate change factors a project done outside of school

\section{$5 \quad$ Conclusion and Implications}

The purpose of this study was to clarify the explicit teaching strategies displayed by an exemplary STEAM teacher, Mr. Kim, during a climate change STEAM program during 10 lessons. This study examined explicit STEAM teaching strategies based on the three stages of a STEAM program suggested by KOFAC (2O17). 
First, explicit teaching in a STEAM program that deals with global issues faced in the community is appropriate for training students to be practical creative problem solvers. In Mr. Kim's STEAM program class, unlike a theory-based class, students had the chance to use ICT media (image media, microscope, tablet PC, carbon dioxide reduction kit, etc.) and participated in the lesson actively when forming concepts based on scientific experimentation and applying these concepts in designing the product, a photobioreactor. Mr. Kim provided students the chance to use tablet PCs, standing boards, and brainistorming with standing boards, when looking for data on climate change, finding information on greenhouse gases, and determining the features of green algae. Mr. Kim's explicit teaching strategies mentioned above included the use of ICT media. This is the focus of the letter "T" in a st EAM program. Mr. Kim also provided students the chance to share and evaluate others' ideas with the use of technology. In the three phases of the sTEAM program, Mr. Kim encouraged students to express their opinions freely and challenge them by exploring what they already knew and what they could learn from the real-life situations. Communicating that focused on "T" and "E" was brought about when designing the product by Mr. Kim continuously inspiring students to think of a practical product that would be helpful to their community. Mr. Kim helped make it possible for students to develop the competencies of collecting data, analyzing information, using information, and using media in order to build the core competencies needed for the various global issues faced in the 21st century. Global problem solving, especially at a given government level, through open questions led students to take responsibility for the community, which kept students motivated and interested in finding the solution. Therefore, future STEAM programs should be presented with more realistic issues arising from the community students belong to. To this end, we propose the development of a program addressing the global issue of seeking specific solutions in STEAM programs.

Second, the climate change STEAM program in this study is appropriate for helping students to become creative problem solvers. Mr. Kim's explicit teaching strategies can promote the critical core competencies suggested by MOE (2015), which include scientific thinking, scientific inquiry, scientific problem solving, scientific communication, scientific engagement, and lifelong learning. The purpose of STEAM education is to equip students with competencies to face and solve global issues. Mr. Kim provided many opportunities for students to experience these science competencies, for example, (1) scientific thinking competency when Mr. Kim encouraged students to make claims with the evidence from their experimentation with the greenhouse effect and 
gases, (2) scientific inquiry competency when Mr. Kim encouraged students to design the investigation to determine more details about global warming and $\mathrm{CO}_{2}$ reduction, (3) scientific problem solving competency when Mr. Kim asked students to determine what the best solution to reduce $\mathrm{CO}_{2}$ for their community is, (4) scientific communication competency when Mr. Kim encouraged students to share their ideas logically and critically when forming concepts from experimentation and when applying concepts for developing a photobioreactor, and (5) scientific engagement and lifelong learning competency when Mr. Kim inspired students to feel responsible to determine the problem and solve it as a community member. Accordingly, explicit teaching strategies should give students the opportunity to achieve core competencies and scientific literacy.

Third, Mr. Kim provided the chance to experience the "A" in STEAM program: The teacher emphasized the discussion of problems students face in the community, solutions that would be the best for their community, and how much they could trust a product as a solution. These discussions gave students feelings of responsibility and equipped students with the ability to evaluate the product from various points of view. Students shared the idea that a photobioreactor had been suggested as being best for the community where chemical factories are located. Students all agreed that chemical plants are appropriate solution for the community, given that green algae consume $\mathrm{CO}_{2}$ through photosynthesis and oil can be obtained by drying green algae. In the emotional experience phase, Mr. Kim also let students experience various human factors in the class from a humanistic perspective for the outcome as the appropriate solution in the community. In order to provide an accurate and efficient STEAM program, teachers should provide opportunities for explicit emotional experience in STEAM programs or practical classroom instruction. Mr. Kim tried to provide chances for students to experience liberal arts, the " $\mathrm{A}$ " in STEAM, in this way.

Fourth, professional development programs for teachers are essential for vitalizing STEAM education. Mr. Kim cannot perform the above explicit teaching strategies on his own. Mr. Kim frequently took workshops and seminars on STEAM offered by MOE and KOFAC. Freely but systematically revising curriculums by collaborating with other teachers in other disciplines is critical in STEAM education. In addition to the theme of climate change, the philosophy and perceptions of STEAM should be newly reorganized through a thorough, situation-based, systematic STEAM teacher training program by sharing the experiences of others who have taught on different themes. In other words, a systematic teacher training program can derive explicit teaching strategies on 
the basis of well-developed STEAM programs. Mr. Kim suggested that experts in STEAM program should be professional in that teachers play the role of leading the STEAM lessons as interactive instead of one way, as collaborator rather than as presenter, with a problem-solving focus rather than answer finding, and as students' exploration instead of teachers' presentation.

\section{Abbreviations}

STEAm Science, Technology, Engineering, Arts, and Mathematics

o-тоP Oregon Collaborative for Excellence in the Preparation [OCE PT] Teaching Observation Protocol

NGSS Next Generation Science Standards

GMOs genetically modified organisms

$\mathrm{CO}_{2} \quad$ carbon dioxide

\section{Acknowledgements}

We would like to thank the anonymous reviewers for their helpful suggestions and feedback.

\section{Ethical Consideration}

The data collected from this project has obtained the necessary clearance from the school(s), guardian(s) and the students involved in the study. The names of the school and participants used in this study are all pseudonyms.

\section{About the Authors}

Young-Shin Park is a Full Professor in the Department of Earth Science Education at Chosun University in Gwangju, Republic of Korea. Professor Park holds a bachelor's degree in Earth Science Education from Seoul National University, and a master degree and doctoral degree in Science Education from Oregon State University in USA. Her research focuses on identifying science teachers' professional practices when teaching using inquiry and scientific argumentation. Professor Park also focuses on docents' professionalism when interacting with visitors in science museums and on identifying their 
competencies for developing science exhibition panels related to science communication.

Jo Hoon Park is a science teacher at Jin Heung Middle School in Gwangju, Republic of Korea. Mr. Park has a degree of bachelor's degree and master degree in Earth Science Education from Chosun University. His research includes promoting science teaching and learning through STEAM program with the focus on global issues. His research also covers the analysis of science communication embedded in the exhibition of natural history museums with a special focus on the topic of dinosaurs.

\section{References}

Baek, Y-S., Kim, Y-M, No, S., Lee, J., Jeong, J., Chae, Y., Han, H., \& Park, H. (2012). Components of $4 \mathrm{C}-\mathrm{STEAM}$ Education and a checklist for the instructional design. Journal of Learner-Centered Curriculum and Instruction. 12(4), 533-557.

Baxter, M., \& Jack, S. (2008). Qualitative Case Study Methodology: Study Design and Implementation for Novice Researchers. The Qualitative Report, 13(4), 544-559.

Chae, H., \& No, S. (2015). Analysis of the conceptual definition in cross-curricular and science core competency. Journal of Learner-Centered Curriculum and Instruction, 15(7), 23-40.

Chae, Y., Jeong, H., \& Kim, D. (2008). 발명영재 교육 및 연구 인프라 구축 방안과 로 드맵 (Road map of education and research infra in invention education for the gifted). Journal of Korean Practical Arts Education, 14(1), 251-270.

Cho, H., Kim, H., \& Heo, J. (2012). Understanding STEAM through on-site applications. A report on pending issues. OR 2012-02-02. Korean Educational Development Institute (KEDI).

Cho, J., Choi, Y., \& Kim, S. (2011). Development of integrative sтEm invention education program model of chemical area. Journal of Korean Practical Arts Education, $17(1), 165^{-188 .}$

Dare, E., Ring-Whalen, E., \& Roehrig, G. (2019). Creating a continuum of STEM models: Exploring how K-12 science teachers conceptualize STEM education. International Journal of Science Education, 41(12), 1701-1720.

Flick, L. B. (1995, April 22-25). Complex instruction in complex classrooms: A synthesis of research on inquiry teaching methods and explicit teaching strategies [Paper presentation]. NARST (National Association for Research in Science Teaching) Annual Meeting, San Francisco, CA, United States.

Heo, J. (2010). 초등학교 교사의 탐구에 대한 신념과 과학과 수행평가의 실제 (The relationship between elementary school teachers' beliefs of inquiry and science 
performance assessment) [Unpublished master's thesis]. Korea National University of Education.

Jeong, D-Y., \& Chang, S-O. (2005). Population as the cause of environmental problems. Korea Journal of Population Studies, 28(1), 313-343.

Jang, H. (2012). Students' perceptions analysis on STEAM education [Unpublished master's thesis]. Inha University of Education.

Jeong, D. (2010). Crisis caused by the development of biotechnology and legislative response. Crisisonomy, 6(2), 214-228.

Kang, E., McCarthy, M., \& Donovan, C. (2015, March 20-21). Enhancing elementary teachers'STEM teaching practice through a NGSS-focused professional development program [Conference presentation]. International Conference of New Perspectives in Science Education, Florence, Italy.

Kang, N., \& Lee, E. (2013). An analysis of inquiry activities in high school physics textbooks for the 2009 revised science curriculum. Journal of the Korean Association for Science Education, 33(1), 132-143.

Kim, S., Ryu, H., \& Cheo, G. (2012). An analysis of the contents and steam educational factors of global issues presented in the 2009 revision of secondary school science curriculum. Journal of Learner-Centered Curriculum and Instruction, 12(2), 73-96.

Korea Foundation for the Advancement of Science and Creativity [KFASC]. (2017). STEAM 프로그램 활용 가이드복 (STEAM Utilization Guidebook). Ministry of Science and Technology and KFAsc.

Lee, H., Son, D., Kwon, H., Park, K., Han, I., Jeong, H., Lee, S., Oh, H., Nam, J., Oh, Y., Bang, S., \& Seo, B. (2012). Secondary teachers' perceptions and needs analysis on integrative STEM education. Journal of Korean Association for Science Education, $32(1), 30-45$.

Lee, Y, \& Han, M. (2010). Social acceptance of scientific technology - a case study of living modified organism. Korean Society for Social History, 13(1), 35-64.

Lee, W, \& Kang, S. (2014). Creative and critical thinking skills-reinforced and STEAM-oriented teaching strategy of science for students' extracurricular activities through a junior high school intervention study program. Subjective Education Research, 18(2), 321-342.

National Research Council (200o). Inquiry and the national science education standards. National Academy Press.

National Research Council (2012). A framework for K-12 science education: Practices, crosscutting concepts, and core ideas. National Academies Press.

Morrell, T., Wainwright, C., \& Flick, L. (2004). Reform teaching strategies used by student teachers. School Science and Mathematics, 104(5), 199-213.

Ministry of Education and Science Technology [MEST]. (2011). Science and curriculum. Ministry of Education, Science and Technology Notice No. 2011-361. MEST. 
Ministry of Education and Science Technology [MEST ]. (2015). Science and curriculum. Ministry of Education, Science and Technology Notice No. 2015-74. MEST.

Park, J., Park, Y-S., Kim, Y., Park, J., \& Jeong, J-S. (2014). The development of the Korean teaching observation protocol (КтоР) for improving science teaching and learning. Journal of Baltic Science Education, 13(2), 259-275.

Park, Y-S. (2012). Convergence talent education (STEAM) program: Final Report. Korea Science Foundation.

Park, Y-S. (2008). Analyzing science teachers' understandings about scientific argumentation in terms of scientific inquiry. Journal of the Korean Association for Science Education, 28(3), 211-226.

Park, Y-S., \& Park. G. (2018). Defining science core competency in the 2015 revised science curriculum and exploring its application into STEAM program. Journal of the Korean Earth Science Society, 39(4), 361-377.

Park, Y-S., \& Green, J. (2019). Bringing computational thinking into science education. Journal of Korean Earth Science Society, 40(4), 340-352.

Pajares, M. F. (1992). Teachers' beliefs and educational research: Cleaning up a messy construct. Review of Educational Research, 62(3), 307-332.

Peterman, F. P. (1991, April). An experienced teacher's emerging constructivist beliefs about teaching and learning. Paper presented at the Annual Meeting of the American Educational Research Association, Chicago.

Tangalakis, K., Hughes, K., Brown, C., \& Dickson, K. (2014). The use of explicit teaching strategies for academic staff and students in bioscience foundation subjects. International Journal of Innovation in Science and Mathematics Education, 22(3), $42-51$.

Son, Y., Jeong, S., Kwon, S., Kim, H., \& Kim, D. (2012). Analysis of prospective and in-service teachers' awareness of STЕAM convergent education. Institutes for Humanities and Social Sciences, 13(1), 255-284.

UNESCO (2005). Shaping the Education of Tomorrow. UNESCO. 